\title{
Risk factors governing the development of cerebral vein and dural sinus thrombosis after craniotomy in patients with intracranial tumors
}

\author{
Florian Gessler, MD, ${ }^{1}$ Markus Bruder, MD, ${ }^{1}$ Stephan Duetzmann, MD, ${ }^{1}$ Stephanie Tritt, MD, ${ }^{2}$ \\ Joshua D. Bernstock, MSc, MPH, ${ }^{3}$ Volker Seifert, MD, PhD, ${ }^{1}$ and Christian Senft, MD, PhD ${ }^{1}$ \\ 1Department of Neurosurgery and 2Institute of Neuroradiology, University Hospital Frankfurt, Goethe-University, Frankfurt, \\ Germany; and ${ }^{3}$ Stroke Branch, National Institute of Neurological Disorders and Stroke, National Institutes of Health, \\ Bethesda, Maryland
}

OBJECTIVE Neurosurgical intervention may increase the risk of developing cerebral vein and dural sinus thrombosis (CVT). The clinical management of CVT in postoperative patients remains unclear. This retrospective study explores the disease occurrence, associated risk factors, and outcomes in patients with tumors who developed CVT after craniotomy.

METHODS A retrospective analysis and review of patient records in those who had undergone cranial tumor removal within the authors' neurosurgical department was performed. In so doing, the authors identified a cohort of patients who developed CVT postoperatively. The study included patients who presented to the department between January 2004 and December 2013.

RESULTS Of 2286 patients with intracranial lesions who underwent craniotomy, 35 (1.5\%) went on to develop CVT. The authors identified the semisitting position (OR 7.55, 95\% Cl 3.73-15.31, $\mathrm{p}<0.001)$; intraoperative sinus injury (OR 1.5, 95\% Cl 3.57-15.76, $p<0.001$ ); and known CVT risk factors (OR 7.77, 95\% Cl 2.28-21.39, p < 0.001) as predictors of CVT development. Of note, 19 patients (54.3\%) had good outcomes (modified Rankin Scale Score 0-1), whereas 9 patients (25.7\%) had suffered dependency or death (modified Rankin Scale Score 4-6) at last follow-up. Intracerebral hemorrhage (OR 21.27, 95\% Cl 1.59-285.01, $p=0.02$ ) and delayed delivery of an intermediate dose of low-molecular-weight heparin anticoagulation (OR 24.12, 95\% Cl 2.08-280.13, $p=0.01$ ) were associated with unfavorable outcomes.

CONCLUSIONS Only a minority of patients undergoing craniotomy for tumor removal develop CVT, and the majority of those who do develop CVT recover well. Early administration of an intermediate dose of low-molecular-weight heparin anticoagulation might be considered once CVT is diagnosed.

https://thejns.org/doi/abs/10.3171/2016.11.JNS161871

KEY WORDS sinus thrombosis; intracranial; neurosurgery; anticoagulation; risk factors; craniotomy; oncology

$\mathrm{T}$ HROMBOSIS of the cerebral veins and dural sinuses is a rare but serious event that may lead to myriad devastating effects within the CNS. The pathogenesis of cerebral vein and dural sinus thrombosis (CVT) has yet to be fully elucidated due to both the inherent variability in the anatomy of the venous system and the paucity of experiments in relevant animal models of CVT. ${ }^{27}$ However, various clinical conditions have been associated with CVT development (e.g., intracranial surgery and tumor compression). ${ }^{29}$

As has been described by Wong et al., ${ }^{33}$ surgery for intracranial neoplasms may be associated with a number of adverse events. Although previous studies have focused on the natural history of $\mathrm{CVT}^{14,25}$ and the importance of specific hazards in selected groups of patients, ${ }^{19,21,22,26}$ the literature lacks a critical assessment of risk factors associated with the development of CVT following neurosurgical removal of an intracranial mass.

Accordingly, herein we examined a large database containing all patients admitted for the removal of an intracranial brain tumor over a 10 -year period, with the aim of investigating risk factors associated with the development of CVT in such a clinical context. In so doing we have highlighted risk factors associated with unfavorable outcomes in an effort to develop a safe pre- and postoperative treatment regimen. Such protocols may ultimately be used in such patients to help prevent and/or manage CVT after a craniotomy.

ABBREVIATIONS CVT = cerebral vein and dural sinus thrombosis; ICH = intracerebral hemorrhage; IQR = interquartile range; ISCVT = International Study on Cerebral Vein and Dural Sinus Thrombosis; LMWH = low-molecular-weight heparin; $m R S$ = modified Rankin Scale.

SUBMITTED July 17, 2016. ACCEPTED November 17, 2016.

INCLUDE WHEN CITING Published online April 7, 2017; DOI: 10.3171/2016.11.JNS161871. 


\section{Methods}

This study received internal review board approval from the local ethics committee. Patient consent was neither sought nor required for this retrospective analysis. We reviewed the records of all patients who had undergone craniotomy after being diagnosed with an intracranial mass between January 1, 2004, and December 31, 2013, for the subsequent development of CVT. After craniotomy for intracranial tumor, our institutional standard of care mandates a follow-up visit at 3 months and regular visits thereafter. For analysis, the last documented clinical status was used. All of the patients with documented CVT who survived to 3 months underwent at least 1 follow-up visit.

Per the aforementioned process, we retrospectively retrieved the following patient parameters: baseline demographics, tumor pathology, histological grading, patient position during surgery, location of the tumor, proximity to a major sinus, sinus compression and/or infiltration, location of craniotomy, duration of surgery, known CVT risk factors (as described below), intraoperative sinus or sinus vein injury, initial clinical manifestations of CVT occurrence, neurological outcome, complications, number of affected sinus vein segments, degree of recanalization at last follow-up, time to diagnosis after surgery, time to intermediate-dose low-molecular-weight heparin (LMWH) anticoagulation after surgery, and time to full therapeutic anticoagulation.

Intraoperative dural sinus or sinus vein injury was considered to have occurred if any direct or indirect signs of injury (e.g., bleeding, visible injury, and/or air embolism) were mentioned in the surgical report. The early versus late initiation of anticoagulation regimens was stratified by the median time observed. The modified Rankin Scale (mRS) scores, assessed at both discharge and last known follow-up, were used for outcome analysis.

We defined the following conditions and syndromes as known medical risk factors: genetic prothrombotic conditions (antithrombin deficiency, protein $\mathrm{C}$ and/or protein $\mathrm{S}$ deficiency, factor $\mathrm{V}$ Leiden mutation, prothrombin mutation, homocysteinemia); acquired prothrombotic states (nephrotic syndrome, antiphospholipid syndrome); infections (otitis, mastoiditis, meningitis); inflammatory diseases (systemic lupus erythematosus, Wegener's granulomatosis, sarcoidosis, inflammatory bowel disease, Behçet's syndrome); hematological conditions (polycythemia, thrombocythemia, leukemia, anemia [hemoglobin level of $<13.5$ $\mathrm{g} / \mathrm{dl}$ in male and $<11.6 \mathrm{~g} / \mathrm{dl}$ in female patients]); and finally, the use of oral contraceptive medication. ${ }^{3,17,29,32}$ We included patients with intracranial WHO III and IV tumors and patients with intracranial masses secondary to metastatic (nonbrain) tumor that were defined as malignant.

Patients diagnosed with CVT underwent laboratory screening for risk factors. Screening was performed after recovery from surgery to avoid false-negative laboratory results due to trauma-induced alterations in patients' coagulation states. Patients in whom thrombophilia was then diagnosed were considered to bear a medical risk factor.

Of note, our institutional standard of care calls for patients to receive prophylactic anticoagulation consisting of LMWH (nadroparine calcium $0.3 \mathrm{ml}$ subcutaneously) from postoperative Day 1 onward. Prophylactic anticonvulsants are not routinely used in patients with newly di- agnosed brain tumors at our academic center; such drugs were only prescribed in patients after the first observed seizure. ${ }^{16}$ Moreover, all patients were admitted to the intensive care unit postoperatively regardless of the development of CVT. Therefore, we defined the intermediate dose of LMWH anticoagulation to be twice that of prophylactic anticoagulation. We defined anti-Xa-level-adjusted anticoagulation as fully therapeutic. During the initiation of treatment, anti-Xa levels were checked to avoid overdosing with LMWH, thereby avoiding a prohemorrhagic state.

All patients underwent imaging on postoperative Day 1 or 2, per the institutional standard. The modality (CT or MRI) depended on the clinical indication. All patients developing clinical signs of a possible CVT underwent MRI and venous MR angiography according to the institutional standard, unless patients were ineligible because of MRI contraindications. In this case patients were diagnosed using CT and venous CT angiography. Venous infarction was defined by the radiological demonstration of CVT and infarction in the affected territory of the venous drainage.

Outcome variables were measured using the mRS at 3 months after onset of illness by an independent neurosurgeon, who did not perform the surgery. For further analysis, patients were stratified into the following groups: "favorable outcome" (mRS Score 0-2) and "unfavorable outcome" (mRS Score 3-6).

\section{Statistical Analysis}

For the purposes of data analysis, patients were dichotomized by the median of the analyzed parameters (i.e., age, duration of surgery, time to diagnosis, and so on). The Mann-Whitney U-test was used for nonparametric analyses. Binary parameters were analyzed using the chisquare test. Multivariable analysis was performed using a binary logistic regression model, which incorporated a backward, stepwise exclusion to identify independent predictors of outcome parameters. Results with a $\mathrm{p}$ value $<$ 0.05 were considered to be statistically significant. Multivariable analysis included parameters identified in univariate analysis with a $\mathrm{p}$ value of $<0.1$. Missing values were processed using a missing-value analysis, followed by a multiple imputation model for outcome parameters. Information on missing values before multiple imputation is given in Supplementary Table 1. All statistical tests were 2-tailed. All calculations were performed using standard commercial software (SPSS version 20, IBM, Inc.).

\section{Results}

We included 2286 patients, of whom 35 (1.53\%) developed CVT during their postoperative clinical course (Table 1).

\section{Morphological and Clinical Characteristics of CVT}

The majority of patients $(57.2 \%)$ suffered CVT that affected multiple sinus segments (Table 2). Further analysis of the segments involved demonstrated that the majority of diagnosed CVTs occurred within the transverse sinus $(54.3 \%)$, sigmoid sinus (48.6\%), and jugular vein $(8.6 \%)$. Only a minority of these 35 patients $(n=11)$ had radiologically confirmed involvement of the cerebral veins $(31.4 \%)$. 
TABLE 1. Overall characteristics in 2286 patients who underwent craniotomy for intracranial lesions

\begin{tabular}{|c|c|c|c|}
\hline Characteristic & $\begin{array}{c}\text { No } \\
\text { CVT }\end{array}$ & CVT & $\begin{array}{c}p \\
\text { Value }\end{array}$ \\
\hline No. of patients & 2251 & 35 & \\
\hline Median age in yrs (IQR) & $54.8(22.8)$ & $47.2(20.1)$ & 0.01 \\
\hline Female sex & $1133(50.3)$ & $23(65.7)$ & 0.09 \\
\hline Tumor entity & & & 0.45 \\
\hline Meningioma & $892(39.6)$ & $18(51.4)$ & \\
\hline High-grade glioma & $676(30.0)$ & $7(20)$ & \\
\hline Low-grade glioma & $65(2.9)$ & $1(2.9)$ & \\
\hline Metastatic tumor & $325(14.4)$ & $7(20)$ & \\
\hline Other & $293(13)$ & $2(5.7)$ & \\
\hline Patient positioning & & & $<0.001$ \\
\hline Supine & $1430(63.5)$ & $12(34.3)$ & \\
\hline Prone & $41(1.8)$ & $0(0)$ & \\
\hline Lateral & $520(23.1)$ & $4(11.4)$ & \\
\hline Sitting/semisitting & $257(11.4)$ & $19(54.3)$ & \\
\hline Other & $3(0.1)$ & $0(0)$ & \\
\hline Location of the tumor & & & 0.17 \\
\hline Intraaxial & 579 & 14 & \\
\hline Extraaxial & 1672 & 21 & \\
\hline $\begin{array}{l}\text { Proximity to a dural sinus/sinus } \\
\text { vein }\end{array}$ & & & 0.46 \\
\hline Distant & 1143 & 20 & \\
\hline Adjacent & 1108 & 15 & \\
\hline Sinus infiltration & & & 0.34 \\
\hline Yes & 139 & 3 & \\
\hline No & 2112 & 32 & \\
\hline Location of craniotomy & & & 0.8 \\
\hline $\begin{array}{l}\text { Distant to dural sinus/sinus } \\
\text { vein }\end{array}$ & 556 & 8 & \\
\hline $\begin{array}{l}\text { Adjacent to or spanning a } \\
\text { dural sinus/sinus vein }\end{array}$ & 1695 & 27 & \\
\hline $\begin{array}{l}\text { Median duration of surgery in } \\
\text { mins (IQR) }\end{array}$ & $155(133)$ & $133(155)$ & 0.37 \\
\hline CVT medical risk factor & $71(3.2)$ & $6(17.1)$ & 0.001 \\
\hline Intraop cerebral vein/sinus injury & $184(8.2)$ & $14(40)$ & $<0.001$ \\
\hline
\end{tabular}

Data are presented as the number of patients (\%) unless otherwise stated. Data comparisons were done using either the Mann-Whitney U-test or chisquare test, where applicable.

Of those, 5 patients had isolated cerebral vein thrombosis, whereas 6 patients displayed combined cerebral vein and dural sinus thrombosis.

Seventeen patients displayed clinical symptoms of CVT development $(48.6 \%)$. Of these patients, 8 reported headaches $(22.8 \%), 7$ displayed neurological deficits (20\%), and 2 reported or displayed other symptoms (5.8\%). In the remaining 18 patients (51.4\%), CVT was diagnosed incidentally via routine postoperative imaging (Table 3 ). Of the patients who developed CVT, 8 (22.9\%) received anticonvulsive medication: of these, 6 patients received levetiracetam, 1 received valproic acid, and 1 received carbamazepine.
TABLE 2. Radiological characteristics in 35 patients who developed CVT

\begin{tabular}{cc}
\hline \multicolumn{1}{c}{ Characteristic } & No. $(\%)$ \\
\hline Segments involved & $15(42.8)$ \\
\hline 1 & $15(42.8)$ \\
\hline 2 & $3(8.6)$ \\
\hline 3 & $2(5.7)$ \\
\hline Sinus thrombosis & $12(34.3)$ \\
\hline Superior sagittal sinus & $6(17.1)$ \\
\hline Confluence of sinuses & $19(54.3)$ \\
\hline Transverse sinus & $17(48.6)$ \\
\hline Sigmoid sinus & $3(8.6)$ \\
\hline Jugular vein & $6(17.1)$ \\
\hline Other & $5(14.3)$ \\
\hline Cerebral vein thrombosis & $6(17.1)$ \\
\hline Isolated cerebral vein thrombosis & $4(11.4)$ \\
\hline Cerebral vein \& dural sinus thrombosis & \\
\hline Venous infarction & $2(5.7)$ \\
\hline ICH & $1(2.9)$ \\
\hline Prior to anticoagulation & \\
\hline During anticoagulation & \\
\hline
\end{tabular}

Nine patients (25.8\%) ultimately developed complications: 4 (11.4\%) suffered a venous infarction, $3(8.6 \%)$ developed an intracerebral hemorrhage (ICH), and 2 (5.8\%) developed other complications (e.g., seizures). The median time to diagnosis of CVT was 2 days (interquartile range [IQR] 1.5 days), the median time from surgery to the start of an intermediate dose of LMWH anticoagulation was 2 days (IQR 2.5 days), and the median time from surgery to start of therapeutic anticoagulation was 7 days (IQR 6 days). Full therapeutic anticoagulation was initiated in 25 patients $(71.4 \%)$, whereas 10 patients $(28.6 \%)$ received long-term intermediate dosing of LMWH.

\section{Risk Factors}

Patients who developed CVT were significantly younger (median age 54.8 years overall [IQR 22.8] vs 47.2 years in patients with CVT [IQR 20.1], $\mathrm{p}=0.01$, univariate); were more likely to have been in the semisitting position during the procedure (OR 8.22, 95\% CI 4.18-16.1, $\mathrm{p}<0.001$, univariate); and had a higher rate of known preoperative medical risk factors for CVT (OR 6.35, 95\% CI 2.56-15.79, $\mathrm{p}$ $=0.001$, univariate) than did patients who did not develop CVT. Furthermore, the intraoperative lesioning of either the cerebral sinuses or veins led to a higher rate of CVT (OR 7.49, 95\% CI 3.75-14.97, $\mathrm{p}<0.001$, univariate). The occurrence of an intraaxial tumor versus a meningioma was not associated with the development of CVT, when compared to other tumors (OR 0.62, 95\% CI 0.31-1.22, $\mathrm{p}=0.17)$. Other parameters such as adjacency to sinus, sinus infiltration, a craniotomy distant to a sinus, duration of surgery longer than 155 minutes, or malignancy were also not associated with the development of CVT (Supplementary Table 2). 
Furthermore, age (OR 0.37, 95\% CI 0.15-0.91, $\mathrm{p}=0.016)$; the semisitting position (OR 7.55, 95\% CI 3.73-15.31, p < 0.001 ); known medical risk factors for CVT (OR 7.77, $95 \%$ CI 2.28-21.39, $\mathrm{p}<0.001$ ); and intraoperative sinus and/or vein injury (OR 7.5, 95\% CI 3.57-15.76, $\mathrm{p}<0.001$ ) were confirmed as independent parameters associated with a higher occurrence of CVT via multivariable analysis (Nagelkerke $\left.\mathrm{R}^{2}=0.227\right)$ (Table 4). Sex $(\mathrm{p}=0.08)$ and tumor pathology (malignant vs nonmalignant tumor) $(\mathrm{p}=0.07)$ were not associated with the development of CVT.

\section{Postoperative Outcomes}

For the assessment of parameters associated with outcome, only patients with CVT were analyzed. All but 5 patients with CVT were available for follow-up at 3 months. The average follow-up of patients with CVT was 181 days (Table 3$)$. At discharge, 16 patients $(45.7 \%)$ recovered (i.e., mRS Score 0-1), 17 (48.6\%) remained in a dependent clinical state, and $2(5.7 \%)$ had died. As of the last follow-up, the majority of patients $(n=26,74.3 \%)$ had recovered from surgery, and fewer patients remained in a dependent state $(\mathrm{n}=6,17.1 \%)$; in total 3 patients $(8.6 \%)$ were dead at the 3-month follow-up.

\section{Risk Factors Predictive of an Unfavorable Neurological Outcome}

Of the parameters recorded, the development of ICH (OR 24, 95\% CI 3.25-177.41, $\mathrm{p}=0.001$ ); a symptomatic CVT (OR 15.33, 95\% CI 2.45-96.09, $\mathrm{p}=0.003$ ); the existence of a malignant tumor (OR 6.88, 95\% CI 1.27-37.34, $\mathrm{p}=0.03$ ); and the late initiation (after postoperative Day 2) of intermediate-dose LMWH anticoagulation (OR 26.83, 95\% CI 3.71-194.18, $\mathrm{p}=0.001$ ) were associated with the development of unfavorable neurological outcome as confirmed via univariate analyses (Supplementary Table 3). Multivariable analysis confirmed ICH (OR 21.27, 95\% CI $1.59-285.01, \mathrm{p}=0.02$ ) and the late initiation of intermediate-dose LMWH anticoagulation (OR 24.12, 95\% CI $2.08-280.13, \mathrm{p}=0.01$ ) as independent risk factors for the development of unfavorable neurological outcomes $\left(\right.$ Nagelkerke $\left.\mathrm{R}^{2}=0.78\right)$ (Table 5). Of note, no differences were observed between patients undergoing long-term intermediate dosing with LMWH and full therapeutic anticoagulation with either LMWH or warfarin $(\mathrm{p}=1)$.

\section{Discussion}

Our study attempted to identify novel risk factors associated with the development of CVT. Furthermore, we have described a proposed treatment regimen that may be used in the event that CVT develops (i.e., acute intermediate-dose LMWH anticoagulative therapy).

The data obtained from our retrospective cohort confirmed both the percentage and mode of clinical presentation previously reported for CVT., $3,23,30$ However, in the International Study on Cerebral Vein and Dural Sinus Thrombosis (ISCVT) conducted by Ferro et al., headaches were observed in $88.8 \%$ of patients developing spontaneous CVT. ${ }^{14}$ To avoid insufficient management of postoperative headaches,${ }^{20}$ our institutional standard of care routinely calls for the administration of postoperative analgesia to
TABLE 3. Clinical characteristics in 35 patients with CVT

\begin{tabular}{|c|c|}
\hline Characteristic & Value \\
\hline Malignancy & $11(31.4)$ \\
\hline Patients w/ anticonvulsive medication & $8(22.9)$ \\
\hline \multicolumn{2}{|l|}{ Symptom } \\
\hline Incidental & $18(51.4)$ \\
\hline Headaches & $8(22.9)$ \\
\hline Neurological deficit & $7(20)$ \\
\hline Other & $2(5.7)$ \\
\hline \multicolumn{2}{|l|}{ Complication } \\
\hline Venous infarction & $4(11.4)$ \\
\hline $\mathrm{ICH}$ & $3(8.6)$ \\
\hline Other & $2(5.7)$ \\
\hline \multicolumn{2}{|l|}{ Median difference in days (IQR) } \\
\hline Time from surgery to diagnosis & $2(1.5)$ \\
\hline Time from surgery to intermediate-dose anticoagulation & $2(2.5)$ \\
\hline Time from surgery to therapeutic anticoagulation & $7(6)$ \\
\hline Therapeutic anticoagulation & $25(71.4)$ \\
\hline \multicolumn{2}{|l|}{ Type of anticoagulation } \\
\hline LMWH & $28(80)$ \\
\hline Unfractionated heparin & $7(20)$ \\
\hline Average follow-up in days (IQR) & $181(109)$ \\
\hline \multicolumn{2}{|l|}{ Outcome on discharge } \\
\hline Complete recovery & $16(45.7)$ \\
\hline Death or dependency & $19(54.3)$ \\
\hline \multicolumn{2}{|l|}{ Outcome on last follow-up } \\
\hline Complete recovery & $26(74.3)$ \\
\hline Death or dependency & $9(25.7)$ \\
\hline
\end{tabular}

Data are presented as the number of patients (\%) unless otherwise stated.

patients, which may hinder the clinical diagnosis of CVT (i.e., via the suppression of a critical presenting symptom). Moreover, seizures were observed in $39.5 \%$ of all patients within the ISCVT. In the course of our study we observed seizure as the initial symptom in only 1 patient. This may be due to the patient population analyzed, which consists only of patients with intracranial tumors; those tumor patients initially presenting with seizures have been receiving anticonvulsant medications, therefore suppressing seizure as a symptom of CVT. Furthermore, crucial methodological differences between the ISCVT and our study exist: we only focus on the initial symptom leading to the diagnosis of CVT, contrary to the study by Ferro et al., which lists all observed symptoms. Most importantly, we present data centered on a highly exclusive patient population, whereas the ISCVT reports data in the format of a cross-sectional trial, thereby limiting the comparability.

The assessment of CVT is associated with difficulties after brain tumor surgery. Therefore, diagnosis of CVT postoperatively in the neurosurgically treated patient predominantly relies on imaging. Both CT and MRI are widely used in the diagnosis of CVT, with MRI displaying a higher sensitivity with regard to the detection of CVT and venous infarction; therefore it is the gold standard in the diagnosis of CVT. ${ }^{4}$ Additionally, postoperative chang- 
TABLE 4. Univariate and multivariate analyses of parameters associated with the development of CVT

\begin{tabular}{|c|c|c|c|c|c|c|}
\hline \multirow[b]{2}{*}{ Parameter } & \multicolumn{3}{|c|}{ Univariate Analysis } & \multicolumn{3}{|c|}{ Multivariate Analysis } \\
\hline & OR & $95 \% \mathrm{Cl}$ & p Value & OR & $95 \% \mathrm{Cl}$ & $\mathrm{p}$ Value \\
\hline Age $>55$ yrs & 0.34 & $0.14-0.83$ & 0.01 & 0.37 & $0.15-0.91$ & 0.016 \\
\hline Female sex & 1.89 & $0.94-3.82$ & 0.09 & & & 0.08 \\
\hline Semisitting position & 8.22 & $4.18-16.1$ & $<0.001$ & 7.55 & $3.73-15.31$ & $<0.001$ \\
\hline Risk factor for CVT & 6.35 & $2.56-15.79$ & 0.001 & 7.77 & $2.28-21.39$ & $<0.001$ \\
\hline Intraaxial tumor location & 0.62 & $0.31-1.22$ & 0.17 & & & \\
\hline Adjacency to sinus & 1.23 & $0.66-2.53$ & 0.46 & & & \\
\hline Sinus infiltration & 1.42 & $0.43-4.7$ & 0.34 & & & \\
\hline Craniotomy distant to sinus & 0.9 & $0.41-2.0$ & 0.80 & & & \\
\hline Surgery longer than 155 mins & 1.35 & $0.67-2.66$ & 0.37 & & & \\
\hline Malignancy & 1.91 & $0.93-3.93$ & 0.07 & & & 0.07 \\
\hline
\end{tabular}

Binary logistic regression with stepwise exclusion was used for multivariate analysis (Nagelkerke $R^{2}=0.227$ ).

es commonly observed in neurosurgically treated patients may impede the diagnosis of CVT in these individuals; therefore, patients who had developed clinically unapparent CVT may have remained undetected within our study. Routine imaging on postoperative Day 1 was performed in all patients as per the institutional standard. Although postoperative imaging may be waived in neurosurgically treated patients with noneloquent tumors who do not display risk factors for the development of CVT, ${ }^{15}$ our data underline the importance of such a postoperative routine, because a significant number of patients were in fact diagnosed during postoperative imaging within this study. It is prudent to note that our institutional standard after removal of intracranial tumor includes T1-weighted spin echo MRI sequences. As has been described, T1-weighted spin echo images provide a reliable tool for the detection of CVT (i.e., with a sensitivity of up to $90 \%) .{ }^{18}$ Despite such robust detection, it remains possible that approximately $10 \%$ of our asymptomatic and/or mildly symptomatic patients may in fact be missed via this imaging paradigm.

Furthermore, within our cohort we have defined a number of risk factors associated with the development of postoperative CVT in patients with intracranial lesions who underwent craniotomy. Whereas some of these factors are indeed modifiable, others are not (e.g., preoperative surgical planning should take into account patient positioning). The semisitting position leads to an increase in cerebral venous drainage, which is beneficial from a surgical point of view, because it leads to a decrease in venous bleeding. ${ }^{6}$ However, the increased venous drainage may lead to the collapse of the cerebral veins and dural sinuses. This is supported by observations that CVT is also a complication observed after lumbar puncture. In those cases, low CSF pressure postpuncture results in a downward shift of the brain, increasing traction on the cortical veins and sinuses, a mechanism by which the semisitting position increases the risk of CVT. ${ }^{1}$

Interestingly, the development of CVT was observed more often in younger patients. This is in line with previous observations: in a study of the general population, $78 \%$ of the cases that resulted in the development of CVT occurred in patients $<50$ years of age. ${ }^{4,7}$ Previously described medical risk factors s, $17,29,32$ were also identified as risk factors for the development of CVT within our population. Of note, the presence of a malignant tumor did not seem to increase the risk of CVT occurrence. This may

TABLE 5. Univariate and multivariate analysis of parameters associated with death or dependency

\begin{tabular}{|c|c|c|c|c|c|c|}
\hline \multirow[b]{2}{*}{ Parameter } & \multicolumn{3}{|c|}{ Univariate Analysis } & \multicolumn{3}{|c|}{ Multivariate Analysis } \\
\hline & OR & $95 \% \mathrm{Cl}$ & $p$ Value & OR & $95 \% \mathrm{Cl}$ & $p$ Value \\
\hline Age $>47$ yrs & 0.933 & $0.2-4.29$ & 1 & & & \\
\hline Female sex & & & 0.685 & & & \\
\hline $\mathrm{ICH}$ & 24 & $3.25-177.41$ & 0.001 & 21.27 & $1.59-285.01$ & 0.02 \\
\hline CVT in $\geq 2$ segments & 1.09 & $0.24-5.03$ & 0.9 & & & \\
\hline Symptomatic CVT & 15.33 & $2.45-96.09$ & 0.003 & & & 0.46 \\
\hline Malignancy & 6.88 & $1.27-37.34$ & 0.03 & & & 0.29 \\
\hline Missing recanalization & 2.18 & $0.3-1.58$ & 0.58 & & & \\
\hline Time to diagnosis $\geq 3$ days & 3.83 & $0.61-24.02$ & 0.16 & & & \\
\hline Time to semitherapeutic anticoagulation $\geq 3$ days & 26.83 & $3.71-194.18$ & 0.001 & 24.12 & $2.08-280.13$ & 0.01 \\
\hline Full therapeutic anticoagulation & 0.83 & $0.13-5.3$ & 1 & & & \\
\hline Time to full therapeutic anticoagulation $\geq 8$ days & 0.44 & $0.07-2.79$ & 0.66 & & & \\
\hline
\end{tabular}

Binary logistic regression with stepwise exclusion was used for multivariate analysis (Nagelkerke $R^{2}=0.78$ ). 
be because we observed different additional risk factors for CVT in intracranial tumors: a large number of patients underwent removal of benign tumors (i.e., meningiomas), which are prone to CVT development due to the nature of their origin and location. ${ }^{22,26}$ On the other hand, malignant tumors are known to express and/or release sizeable amounts of procoagulative factors,,$^{12}$ which result in a high incidence of deep vein thrombosis and pulmonary embolism. ${ }^{24}$ Although patients with meningiomas at certain locations (e.g., parafalcine) have been demonstrated to be at risk for the development of CVT, ${ }^{26}$ our data did not demonstrate an association with meningioma in general and the development of CVT. Taken together, this may indeed explain why no statistical differences were observed between patients undergoing the resection of benign or malignant intracranial tumors.

Intraoperatively, several factors must be considered in an effort to minimize the development of CVT. They include the maintenance of adequate hydration, minimization of the exposure of the sinuses, and the avoidance of dominant sinus sacrifice. ${ }^{19,28}$ We report a fairly high rate of sinus and sinus vein injury in our patient population. We attribute this high rate to the retrospective nature of this study; the operating reports were screened for any note of (i.e., even minor) reports of injury to sinus vein structures that resulted in bleeding. All of these patients were considered to have suffered an injury to a sinus structure, resulting in a rate of injury $>8 \%$. Although this might result in an overestimation of cases, homogeneity within the study population was maintained.

A number of medical approaches for the clinical treatment of CVT exist and include intravenous heparin therapy, ${ }^{13}$ direct endovascular thrombolytic therapy, ${ }^{2,31}$ and/ or the use of LMWH. ${ }^{11}$ Furthermore, patients developing CVT with impending herniation may also be treated surgically via decompressive hemicraniectomy. ${ }^{9}$ Clearly, the risks of postoperative hemorrhage versus CVT progression must be weighed against each other.

The initiation of anticoagulation is considered safe in patients with $\mathrm{CVT},{ }^{8}$ and our study provides further confirmation with regard to neurosurgically treated patients. We have shown that an initiation of intermediate-dose LMWH later than postoperative Day 2 in patients with diagnosed CVT may lead to an increased risk of unfavorable neurological outcomes. It is therefore tempting to speculate that the beneficial effects observed are due to a decrease in the appositional growth of the initiating thrombus. ${ }^{13}$ Interestingly, a fully therapeutic anticoagulative state did not result in a more favorable outcome. It is important to remember that the development of ICH was associated with unfavorable neurological outcome in our study; an observation previously reported in nonneurosurgically treated patients with CVT. ${ }^{10,14}$ Because risk factors for CVT development and poor outcome include parameters not attributable to a tumor burden (e.g., semisitting position or sinus injury), the results of our study may ultimately be generalizable and relevant for neurosurgically treated patients undergoing craniotomy for other indications (e.g., vascular diseases and/or malformations). However, when assessing the outcome, in particular for patients with gliomas, it is difficult to ascertain if disability is due to the tumor or to CVT.

\section{Limitations of the Study}

Due to the retrospective nature of our study and the potential for bias (i.e., data were collected and analyzed retrospectively) all generalizations and clinical recommendations must be made with caution. For example, we note that CVT risk factors are more likely to be elicited and recorded in patients who develop CVT, whereas such risk factors may be underestimated in patients without complications. It is also important to note that the diagnostic criteria for CVT relied on patient charts and/or radiological documentation, because specific rescreening of images for CVT was not performed. Moreover, CVT can be asymptomatic, or it can produce symptoms that are thought to be caused by the tumor surgery. Therefore, our study may underestimate the prevalence of postoperative CVT. Nevertheless, the conclusions drawn with regard to the parameters influencing the development of CVT and clinical outcomes in patients should remain valid. All conclusions regarding anticoagulation need to be carefully discussed due to the retrospective nature of this study and the limitations named above. Because extended diagnostics for medical risk factors were only performed in patients who developed CVT or who had a history of thrombosis or CVT, this might potentially lead to a bias. The main strength of our single-center study is the inclusion of a large number of consecutively treated patients and the extensive period of surgical follow-up.

\section{Conclusions}

We have provided a detailed set of data, which define the postoperative rates of CVT following craniotomy for patients with tumors in a large retrospective case series in an effort to advance neurooncological surgery. In so doing we hope to bring effective CVT interventions to bear. The data presented identify independent risk factors for the development of CVT and further highlight those that are associated with unfavorable neurological outcomes. Although only a small minority of patients undergoing craniotomy for tumor removal go on to develop CVT, pertinent risk factors (e.g., patient position) should be taken into account when developing a neurosurgical plan.

\section{Acknowledgments}

We gratefully acknowledge the excellent assistance with the preparation of the tables provided by Marina Heibel. Furthermore, we thank Karin Ammersbach for assistance with database management.

\section{References}

1. Aidi S, Chaunu MP, Biousse V, Bousser MG: Changing pattern of headache pointing to cerebral venous thrombosis after lumbar puncture and intravenous high-dose corticosteroids. Headache 39:559-564, 1999

2. Barnwell SL, Higashida RT, Halbach VV, Dowd CF, Hieshima GB: Direct endovascular thrombolytic therapy for dural sinus thrombosis. Neurosurgery 28:135-142, 1991

3. Bousser MG, Chiras J, Bories J, Castaigne P: Cerebral venous thrombosis-a review of 38 cases. Stroke 16:199-213, 1985

4. Bousser MG, Ferro JM: Cerebral venous thrombosis: an update. Lancet Neurol 6:162-170, 2007

5. Buonanno FS: Cerebral sinovenous thrombosis. Curr Treat Options Cardiovasc Med 3:417-427, 2001 
6. Campkin TV: Posture and ventilation during posterior fossa and cervical operations. Current practice in the United Kingdom. Br J Anaesth 53:881-884, 1981

7. Canhão P, Ferro JM, Lindgren AG, Bousser MG, Stam J, Barinagarrementeria F: Causes and predictors of death in cerebral venous thrombosis. Stroke 36:1720-1725, 2005

8. Coutinho J, de Bruijn SF, Deveber G, Stam J: Anticoagulation for cerebral venous sinus thrombosis. Cochrane Database Syst Rev (8):CD002005, 2011

9. Coutinho JM, Majoie CB, Coert BA, Stam J: Decompressive hemicraniectomy in cerebral sinus thrombosis: consecutive case series and review of the literature. Stroke 40:22332235,2009

10. de Bruijn SF, de Haan RJ, Stam J: Clinical features and prognostic factors of cerebral venous sinus thrombosis in a prospective series of 59 patients. J Neurol Neurosurg Psychiatry 70:105-108, 2001

11. de Bruijn SF, Stam J: Randomized, placebo-controlled trial of anticoagulant treatment with low-molecular-weight heparin for cerebral sinus thrombosis. Stroke 30:484-488, 1999

12. Dützmann S, Gessler F, Harter PN, Gerlach R, Mittelbronn $\mathrm{M}$, Seifert V, et al: The pro-migratory and pro-invasive role of the procoagulant tissue factor in malignant gliomas. Cell Adhes Migr 4:515-522, 2010

13. Einhäupl KM, Villringer A, Meister W, Mehraein S, Garner C, Pellkofer M, et al: Heparin treatment in sinus venous thrombosis. Lancet 338:597-600, 1991

14. Ferro JM, Canhão P, Stam J, Bousser MG, Barinagarrementeria F: Prognosis of cerebral vein and dural sinus thrombosis: results of the International Study on Cerebral Vein and Dural Sinus Thrombosis (ISCVT). Stroke 35:664-670, 2004

15. Geßler F, Dützmann S, Quick J, Tizi K, Voigt MA, Mutlak $\mathrm{H}$, et al: Is postoperative imaging mandatory after meningioma removal? Results of a prospective study. PLoS One 10:e0124534, 2015

16. Glantz MJ, Cole BF, Forsyth PA, Recht LD, Wen PY, Chamberlain MC, et al: Practice parameter: anticonvulsant prophylaxis in patients with newly diagnosed brain tumors. Report of the Quality Standards Subcommittee of the American Academy of Neurology. Neurology 54:1886-1893, 2000

17. Green D, Otoya J, Oriba H, Rovner R: Protein S deficiency in middle-aged women with stroke. Neurology 42:1029-1033, 1992

18. Idbaih A, Boukobza M, Crassard I, Porcher R, Bousser MG, Chabriat H: MRI of clot in cerebral venous thrombosis: high diagnostic value of susceptibility-weighted images. Stroke 37:991-995, 2006

19. Keiper GL Jr, Sherman JD, Tomsick TA, Tew JM Jr: Dural sinus thrombosis and pseudotumor cerebri: unexpected complications of suboccipital craniotomy and translabyrinthine craniectomy. J Neurosurg 91:192-197, 1999

20. Kim YD, Park JH, Yang SH, Kim IS, Hong JT, Sung JH, et al: Pain assessment in brain tumor patients after elective craniotomy. Brain Tumor Res Treat 1:24-27, 2013

21. Lega BC, Yoshor D: Postoperative dural sinus thrombosis in a patient in a hypercoagulable state. Case report. J Neurosurg 105:772-774, 2006

22. Mantovani A, Di Maio S, Ferreira MJ, Sekhar LN: Management of meningiomas invading the major dural venous sinuses: operative technique, results, and potential benefit for higher grade tumors. World Neurosurg 82:455-467, 2014

23. Paciaroni M, Palmerini F, Bogousslavsky J: Clinical presentations of cerebral vein and sinus thrombosis. Front Neurol Neurosci 23:77-88, 2008

24. Prell J, Rachinger J, Smaczny R, Taute BM, Rampp S, Illert J, et al: D-dimer plasma level: a reliable marker for venous thromboembolism after elective craniotomy. J Neurosurg 119:1340-1346, 2013
25. Preter M, Tzourio C, Ameri A, Bousser MG: Long-term prognosis in cerebral venous thrombosis. Follow-up of 77 patients. Stroke 27:243-246, 1996

26. Raza SM, Gallia GL, Brem H, Weingart JD, Long DM, Olivi A: Perioperative and long-term outcomes from the management of parasagittal meningiomas invading the superior sagittal sinus. Neurosurgery 67:885-893, 2010

27. Schaller B, Graf R: Cerebral venous infarction: the pathophysiological concept. Cerebrovasc Dis 18:179-188, 2004

28. Spetzler RF, Daspit CP, Pappas CT: The combined supra- and infratentorial approach for lesions of the petrous and clival regions: experience with 46 cases. J Neurosurg 76:588-599, 1992

29. Stam J: Thrombosis of the cerebral veins and sinuses. N Engl J Med 352:1791-1798, 2005

30. Sun Y, Zheng DY, Ji XM, Weale P, Wu H, Jiang LD, et al: Diagnostic performance of magnetic resonance venography in the detection of recanalization in patients with chronic cerebral venous sinus thrombus. Chin Med J (Engl) 122:24282432, 2009

31. Tsai FY, Wang AM, Matovich VB, Lavin M, Berberian B, Simonson TM, et al: MR staging of acute dural sinus thrombosis: correlation with venous pressure measurements and implications for treatment and prognosis. AJNR Am J Neuroradiol 16:1021-1029, 1995

32. Wechsler B, Vidailhet M, Piette JC, Bousser MG, Dell Isola $\mathrm{B}$, Blétry O, et al: Cerebral venous thrombosis in Behçet's disease: clinical study and long-term follow-up of 25 cases. Neurology 42:614-618, 1992

33. Wong JM, Panchmatia JR, Ziewacz JE, Bader AM, Dunn IF, Laws ER, et al: Patterns in neurosurgical adverse events: intracranial neoplasm surgery. Neurosurg Focus 33(5):E16, 2012

\section{Disclosures}

The authors report no conflict of interest concerning the materials or methods used in this study or the findings specified in this paper.

\section{Author Contributions}

Conception and design: Gessler. Acquisition of data: Gessler, Dützmann, Tritt, Bernstock. Analysis and interpretation of data: Gessler, Bruder, Bernstock, Senft. Drafting the article: Gessler, Bruder. Critically revising the article: Gessler, Bruder, Bernstock, Senft. Reviewed submitted version of manuscript: all authors. Approved the final version of the manuscript on behalf of all authors: Gessler. Statistical analysis: Gessler. Administrative/technical/material support: Seifert, Senft. Study supervision: Seifert, Senft.

\section{Supplemental Information \\ Online-Only Content}

Supplemental material is available with the online version of the article.

Supplementary Tables 1-3. https://thejns.org/doi/suppl/10. 3171/2016.11.JNS161871.

\section{Previous Presentations}

Parts of this work were presented in oral and abstract form at the neurooncology section meeting of the German Society for Neurosurgery, which was held in Goettingen, Germany, in 2013.

\section{Correspondence}

Florian Gessler, Department of Neurosurgery, Goethe-University, Schleusenweg 2-16, Frankfurt 60528, Germany. email: f.gessler@ med.uni-frankfurt.de. 